\title{
发光材料新成员一一白光凝胶的现状与未来
}

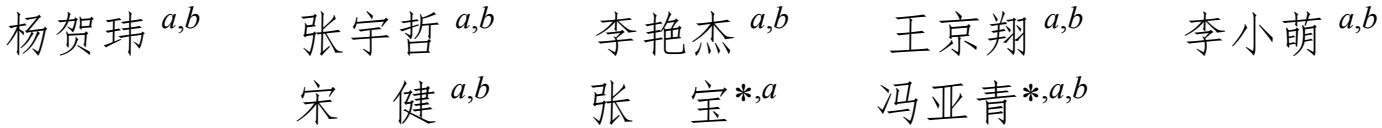 \\ $\left({ }^{a}\right.$ 天津大学化工学院 天津 300072$)$ \\ ( ${ }^{b}$ 天津大学 天津化工协同创新中心 天津 300072)
}

\begin{abstract}
摘要 白光发射材料由三种三原色(红、绿、蓝)发色体或一种三原色与一种补充色(橙色或者绿色)发色体组成, 可以覆 盖整个可见光区 $(380 \sim 750 \mathrm{~nm})$. 白光凝胶是一类具有液体流动性和固体可塑性的白色发光材料, 合成成本低, 易于加 工，使用方式灵活. 将不同发色团化合物凝胶化，有助于供受体分子的靠近、偶极方向的一致和供体发射光谱与受体吸 收光谱的重叠, 实现更好的分子间能量转移, 获得可调控的白光. 重点从能量转移的角度, 介绍以纯有机化合物、有机 金属配位化合物、稀土金属离子等作为受体发色团的白光凝胶的研究现状，并对其在白光显示、智能材料等领域的应 用进行展望.
\end{abstract}

关键词 白光发射; 凝胶; 能量转移

\section{New Member of Luminescent Materials___ Status and Future of White Light Emitting Gel}

\author{
Yang, Hewei ${ }^{a, b}$ \\ Zhang, Yuzhe ${ }^{a, b}$ \\ $\mathrm{Li}$, Yanjie $\mathrm{e}^{a, b}$ \\ Wang, Jingxiang ${ }^{a, b}$ \\ Li, Xiaomeng ${ }^{a, b}$ \\ Song, Jian ${ }^{a, b}$ \\ Zhang, $\mathrm{Bao}^{*, a}$ \\ Feng, Yaqing ${ }^{*, a, b}$ \\ $\left({ }^{a}\right.$ School of Chemical Engineering and Technology, Tianjin University, Tianjin 300072) \\ ( ${ }^{b}$ Collaborative Innovation Center of Chemical Science and Engineering, Tianjin University, Tianjin 300072)
}

\begin{abstract}
White light emission materials consist of components emitting three primary colors (red, green and blue) or two complementary colors (orange or green), which can cover the entire visible region $(380 \sim 750 \mathrm{~nm})$. White light emitting gel with the solution flow character and solid plasticity has the advantages of low cost, easy processing and flexible use. Gelation of components with different emission colors will help the donor and receptor molecule to get closer, contribute to the dipole direction and overlap the emission spectra of the donor and the absorption spectra of the receptor, which promotes molecular energy transfer to achieve better performance of white light emitting. Here we focus on the resonance energy transfer and introduce the white light emitting gel with the receptor chromophore of organic compounds, organic metal complexes and rare earth metal ions. In the end the future prospects of white light emitting gel are proposed.
\end{abstract}

Keywords white light emitting; gel; energy transfer

近年来，白光发射新材料因在照明、智能材料等领 域的潜在应用价值越来越受到研究者的关注 ${ }^{[1 \sim 3]}$, 如白 光溶液 ${ }^{[4,5]}$ 、白光纳米颗粒 ${ }^{[6 ~ 8]}$ 、白光囊泡 ${ }^{[9]}$ 、白光离子 液体 ${ }^{[10]}$ 、白光凝胶 ${ }^{[1]}$ 等. 其中, 白光凝胶是一类具有液 体流动性能和固体可塑性能的发光材料, 由于其合成成 本低、易于加工、使用方式灵活、具有其他发光材料无
法比拟的优势而受到人们的关注 ${ }^{[11]}$. 目前关于发光凝胶 的研究比较广泛, 但是白光凝胶的报道却很少 ${ }^{[12,13]}$. 本 文从发光机理角度，按照受体类型对白光凝胶进行分 类，依次介绍以纯有机化合物、有机金属配位化合物、 稀土离子为受体的白光凝胶的研究现状，并对白光凝胶 的应用前景进行展望.

* Corresponding authors. E-mail: baozhang@tju.edu.cn; yqfeng@tju.edu.cn

Received February 25, 2017; revised April 24, 2017; published online May 2, 2017.

Project supported by the National Natural Science Foundation of China (Nos. 21476162, 21676185) and the International S \& T Cooperation Project of China (Nos. 2012DFG41980, 2016YFE0114900).

国家自然科学基金(Nos. 21476162, 21676185)和科技部国际合作(Nos. 2012DFG41980, 2016YFE0114900)资助项目. 


\section{1 白光发射机理}

材料发光机理如图 1 所示, 分子在光的照射下电子 由基态跃迁到激发态. 激发态电子回到基态并将能量以 光的形式释放, 称为光致发光. 激发态有单重态和三重 态之分, 电子由激发单重态回到基态发出苂光并放出热 量; 由激发三重态回到基态发出磷光. 磷光的寿命要远 远长于苂光的量子寿命.

激发态电子除了以光和热的形式释放, 激发态能量 还能使其他的基态分子跃迁到激发态, 这个过程被称为 能量转移 ${ }^{[14]}$. 其中, 转移能量的分子被称为供体, 接受 能量的分子被称为受体. 能量转移分为光子的发射与再 吸收实现的辐射能量转移及供体激发态到受体基态实 现的非辐射能量转移 ${ }^{[15]}$. 对纳米级有机材料的能量转 移, 主要以非辐射的方式进行, 包括德克斯特(Dexter) 电子交换机理与福斯特(Föster)能量转移机理 ${ }^{[16]}$, 如图 2 所示.

不同颜色球体代表自旋方向相反的电子. 当供体和
受体距离在 $1 \mathrm{~nm}$ 内，供受体间的电子云重叠，产生电子 交换，实现供体激发态能量到受体基态的转移，被称为 Dexter 机理 ${ }^{[16]}$. 当供体和受体的距离在 $1 \sim 10 \mathrm{~nm}$, 受激 发态供体和基态受体的库仑力的促进，会发生 Föster 能 量转移. 这是一种远程的共振相互作用, 即当一个分子 的电子在最高占有轨道 $(\mathrm{HOMO})$ 与最低未占有轨道 (LUMO)之间跃迁时引起另一个分子的共振, 使另一分 子的电子在 $\mathrm{HOMO}$ 与 LUMO 之间跃迁. Föster 能量转移 机理发生在供体的单线态和受体的单线态之间，条件是 受体与供体的光谱重叠, 供受体偶极的相对取向一致 [17]. 光量子寿命是描述激发态分子的发射光由最高强 度降到 $1 / e$ 所需的时间. 苂光强度和光量子寿命是衡量 非辐射能量转移的两个指标 ${ }^{[18]}$.

单一跃迁途径所发射的荧光或磷光是单色光，能量 转移体系中同时存在供受体的激发态，即具有两种或以 上波长的发射光，形成复合光. 当不同色光的比例合适， 则会得到白光. 为了对发射光颜色进行更好的描述，国 际照明委员会(CIE，Commission Internationale de L'E

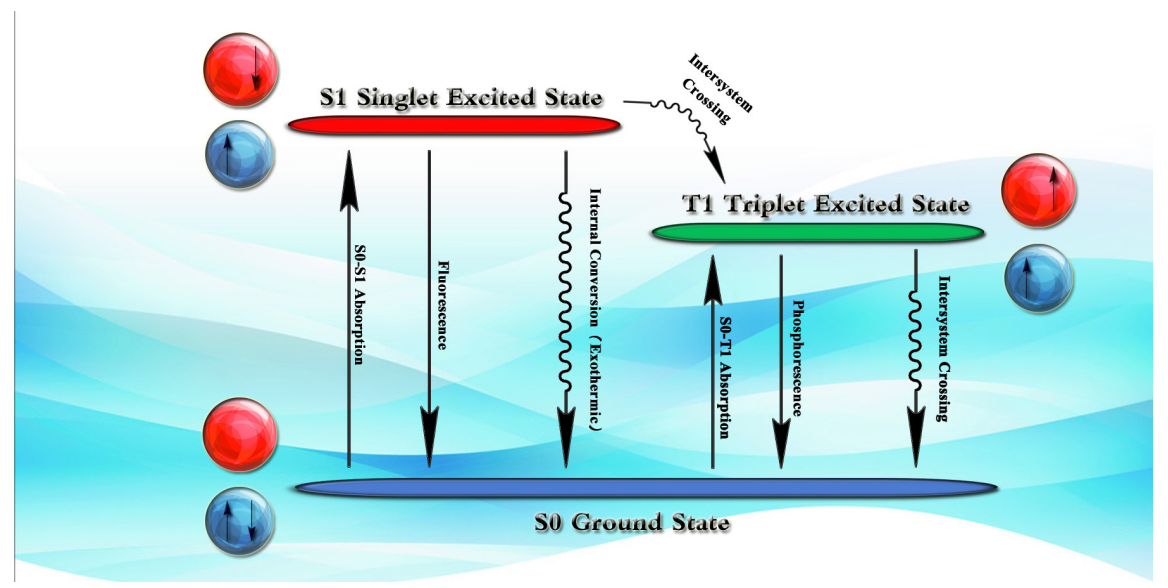

图 1 能态变化示意图

Figure 1 Schematic diagram of energy state change

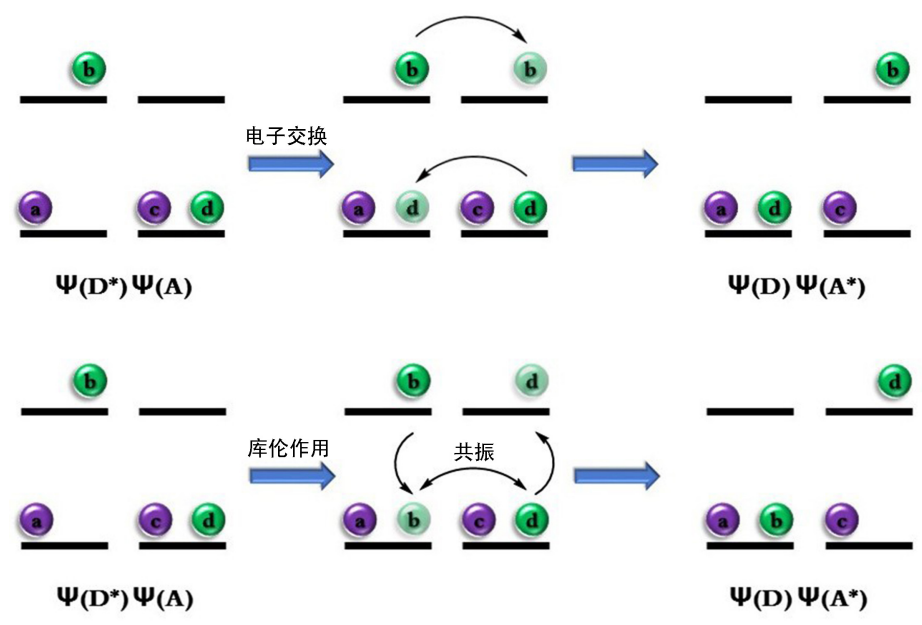

图 2 供体(D)与受体(A)间德克斯特(上)与福斯特(下)能量转移机理示意图

Figure 2 Schematic diagram of Dexter (up) and Forster (down) energy transfer mechanism between donor (D) and acceptor (A) 
clairage $)^{[19]}$ 根据色度学理论将所有颜色用坐标表示(CIE 坐标), 并规定理想白光的坐标为 $(0.333,0.333)$, 器件的 CIE 坐标越接近理想白光, 得到的白光质量越高.

\section{2 纯有机化合物为受体的白光凝胶体系}

具有共轭结构的有机分子可以形成线性 $\pi$ 堆积体. 非共价相互作用提供了分子间电子传输的机会, 使堆积 体轨道分布相较于单体发生改变, 发射光波长发生移 动 ${ }^{[20]}$.

第一篇关于白光凝胶的报道是 2-亚乙烯基-亚苯基 衍生物通过自身单体和堆积体的转变, 实现对于光谱的 调节 ${ }^{[20]} .2007$ 年, Ajayaghosh 等 ${ }^{[21]}$ 发现 2-亚乙烯基-亚苯 基衍生物 $1 \mathrm{a}$ 在环己烷溶液中存在游离的单体和 $\pi-\pi$ 作 用形成的堆积体两种形式, 而在环已烷凝胶中只存在堆 积体. $1 \mathrm{~b}$ 与 $1 \mathrm{a}$ 堆积体的光谱重叠性更好, 可以通过偶 极-偶极相互作用实现 $1 \mathrm{a}$ 堆积体到 $\mathbf{1 b}$ 的能量转移. 用 $380 \mathrm{~nm}$ 的光激发 $\mathbf{1 b}$ 溶液或用 $530 \mathrm{~nm}$ 的光激发含 $\mathbf{1 b}$ 的 $1 \mathbf{a}$ 凝胶, 发射光谱中 $\mathbf{1 b}$ 的特征峰强度很低, 而用 380 $\mathrm{nm}$ 的光激发含 $\mathbf{1 b}$ 的 $\mathbf{1 a}$ 凝胶可以得到和 $530 \mathrm{~nm}$ 的光激 发 $1 \mathrm{~b}$ 溶液一样的发射强度, 很好地说明了受体苂光发 射的能量来自供体堆积体激发态, 而并非自身吸收. 掺 有 $1 \mathrm{~b}$ 的 $1 \mathrm{a}$ 凝胶发射颜色受到温度影响. 低温下, 堆积 体稳定存在, 发生着供体到受体的能量转移, 形成红色 特征发射; 温度升高, 堆积体解体, 出现单体的蓝色特 征发射. $50 \sim 60{ }^{\circ} \mathrm{C}$ 时, 单体与堆积体共存, 体系中存在 着供体到受体的能量转移产生的红光, 堆积体的绿光和 单体的蓝光, 进而形成白光.

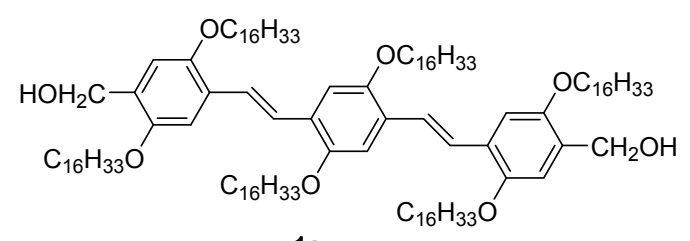

$1 \mathrm{a}$

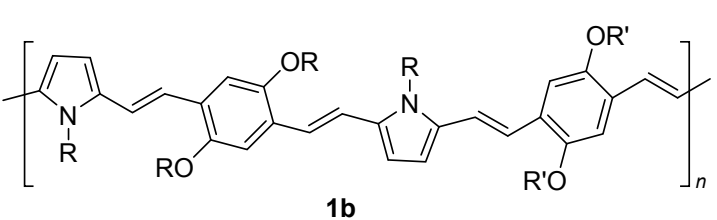

1b

2009 年, Ajayaghosh 等 ${ }^{[22]}$ 以 2-亚乙烯基-亚苯基低 聚物 $2 \mathbf{a}$ 和 $2 \mathbf{b}$ 为供体, 得到两种强度不同的蓝色苂光凝 胶, 加入红光低聚物 $1 \mathrm{~b}$ 作为受体, 研究表明以假 $\mathrm{H}$ 堆积 形成扭曲结构的 $2 \mathrm{a}$, 存在堆积体在 492 和 $528 \mathrm{~nm}$ 的发 射峰与单体在 $464 \mathrm{~nm}$ 的发射峰, 随着 $1 \mathrm{~b}$ 加入, 混合凝 胶的最低成胶浓度逐渐降低, 492 和 $528 \mathrm{~nm}$ 的发射强度 发生 $63 \%$ 的猝灭, $464 \mathrm{~nm}$ 的蓝光发射强度不变, 同时受 体在 $607 \mathrm{~nm}$ 处的特征峰出现. 2a 的光量子寿命由双指

数衰减 $2.38(79.6 \%)$ 和 $3.79 \mathrm{~ns}(20.4 \%)$ 变为 $1.85(93 \%)$ 和 $0.57 \mathrm{~ns}(7 \%)$, 证明了受体加入对堆积体形成的促进与 分子间能量转移的存在. $1 \mathrm{~b}$ 含量为 $x=0.02$ 时, 凝胶发 生 400 700 nm 的大范围苂光发射, 包含供体单体的蓝 光, 供体堆积体的绿光和受体的红光, 混合光颜色接近 白色, CIE 坐标 $(0.28,0.34)$. 而以 $J$ 堆积形成盘旋结构的 $\mathbf{2 b}$, 具有更高的强度和不同于 $\mathbf{2} \mathbf{a}$ 的激发态偶极方向, 激 子扩散迅速, 促进能量向受体转移, 产生过强的红色组 分, 无法得到白色凝胶.

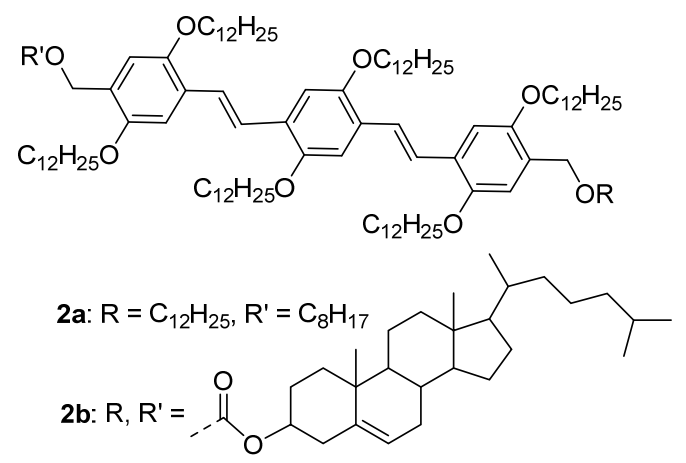

多苯环类化合物能够有效减小单线态和三线态的 带隙差，具有很好的光量子产率．通过在多苯环类化合 物上引入长烷基链能够控制其堆积性能, 制备凝胶 ${ }^{[23]}$. $3 \mathbf{a}$ 在二甲基亚砜(DMSO)凝胶和甲醇凝胶中发蓝光，光 量子产率是 $24 \%$ 与 $8 \%$, 引入量子产率 $69 \%$ 的绿光发色 才 $3 \mathbf{b}$ 和量子产率 $53 \%$ 的红光发色团 $3 \mathrm{c}$ 后, $3 \mathrm{a}$ 发白光, 量子产率变为 $26 \%$ 和 $11 \%, \mathrm{CIE}$ 坐标 $(0.319,0.332)$ 和 $(0.306,0.331)^{[24,25]}$. 在溶液中, 由于光谱重叠性不好, 只存在 $3 b$ 到 $3 \mathrm{c}$ 的能量转移, 不存在 $3 \mathrm{a}$ 向 $3 \mathrm{~b}$ 和 $3 \mathrm{c}$ 的能 量转移. 但是在凝胶中, $3 \mathrm{a}$ 形成了纳米纤维结构, 光谱 红移, 3a 与 3b、3c 之间的光谱重叠促进能量转移, 体系 中同时存在 $3 a$ 到 $3 b, 3 a$ 到 $3 c$ 和 $3 b$ 到 $3 c$ 的能量转移.

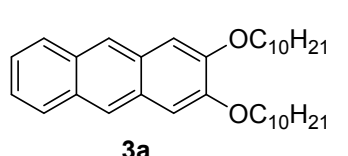

$3 a$

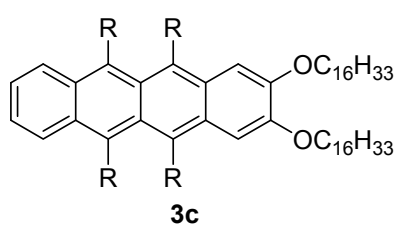

Schenning 等 ${ }^{[26]}$ 研究了 5 种带有 3,4,5-三一十二烷基 苯甲酰胺结构的芴基低聚物在极性溶剂中的自组装行 为. 在甲基环已烷中, $4 \mathrm{a}$ 和 $4 \mathrm{e}$ 形成蓝色与红色凝胶, $4 \mathrm{~b}$ 、 4c、4d 形成蓝色、绿色与黄色溶液. 在 $4 a$ 中混合少量 
的 $4 \mathrm{c} 、 4 \mathrm{~d} 、 4 \mathrm{e}$ (摩尔比 $4 \mathrm{a}: 4 \mathrm{c}: 4 \mathrm{~d}: 4 \mathrm{e}=4.5: 0.7: 0.2 ：$ $0.1)$, 可以得到白光凝胶, $4 \mathbf{a}$ 的量子寿命从 $0.93(94.5 \%)$ 和 $1.81 \mathrm{~ns}(5.5 \%)$ 缩短到 0.28 (95.4\%)和 $1.10 \mathrm{~ns}(5.6 \%)$, 证实了供体 $4 a$ 到 $4 b 、 4 c 、 4 d$ 的能量转移.

用不发光的凝胶因子构建凝胶网络, 将发色团组合 在凝胶网络中, 也可以实现白光发射. Nandi 等 ${ }^{[27,28]}$ 以三 聚氰胺 5a 为凝胶因子, 掺杂 6,7-二甲氧基-2,4[1 $H, 3 H]-$ 喹喔啉二酮 $5 \mathbf{b}$ 和维生素 B2 5c, 制备了能够在很宽的温 度和 $\mathrm{pH}$ 范围响应的超分子发光水凝胶, 并将罗丹明 $\mathbf{5 d}$ 作为红光受体引入体系, 用 Stern-Volmer 方程证明了体 系中供体自身激发态到基态的静态荧光猝灭和供体激 发态的能量转移到受体发生的动态苂光猝灭同时存在. 在溶液中发生 $5 \mathrm{~b}$ 到 $5 \mathrm{c}$ 再到 $5 \mathrm{~d}$ 的能量转移; 在凝胶中,
$5 b$ 和 5d 的分子间距离缩短, $5 b$ 的发射光谱相较于溶液 态发生了 $50 \mathrm{~nm}$ 的红移, 与 $\mathbf{5 d}$ 的吸收光谱重叠, 存在 $5 b$ 到 5c、5d, 5c 到 5d 的能量转移. 在混合凝胶中, 将 5a、5b、5c、5d 按照 $100 ： 100 ： 0.5 ： 0.02$ 混合可以制 备白光凝胶, CIE 坐标 $(0.31,0.36)$.

Patra 等 ${ }^{[29]}$ 将聚合物 $6 \mathbf{a}$ 、五苯基环戊二烯 $6 \mathbf{b}$ 和二萘 嵌苯 $6 \mathbf{c}$ 溶解在四氢呋喃(THF)中, 得到白光发射溶液, CIE 坐标 $(0.34,0.31)$; 加水后析出白光纳米颗粒, CIE 坐 标 $(0.29,0.32)$; 以琼脂糖为凝胶剂, 可以实现纳米颗粒 悬浊液的凝胶化, 得到白光凝胶, CIE 坐标 $(0.31,0.28)$; 将白光凝胶通过成膜工艺加工，可以制成白光薄膜， $\mathrm{CIE}$ 坐标 $(0.33,0.32)$; 实现了白光溶液、白光纳米颗粒、 白光凝胶和白光薄膜的一系列制备.

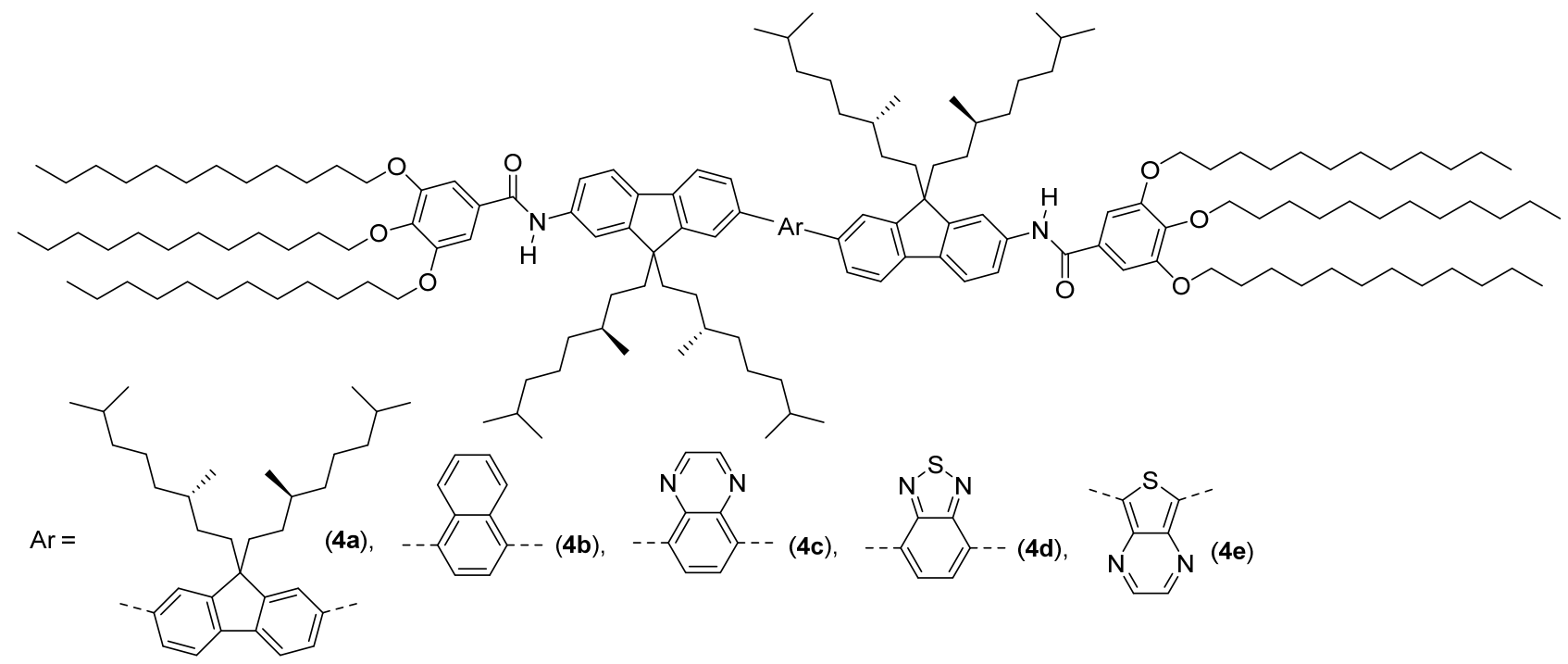<smiles>Nc1nc(N)nc(N)n1</smiles><smiles>COc1cc2[nH]c(=O)[nH]c(=O)c2cc1OC</smiles>

5b<smiles>Cc1cc2nc3c(=O)[nH]c(=O)nc-3n(C[C@H](O)[C@H](O)[C@H](O)CO)c2cc1C</smiles><smiles>CCCCCCCCCC1(CCCCCCCC)C(c2ccc(-c3ccc(C)c4nsnc34)cc2)=C(c2ccc(-c3ccc(C)c4nsnc34)cc2)C(c2ccc(-c3ccc(C)c4nsnc34)cc2)=C1c1ccc(-c2ccc(C)c3nsnc23)cc1</smiles>

$5 c$

<smiles>CCN(CC)c1ccc2c(-c3ccccc3C(=O)O)c3ccc(=[N+](CC)CC)cc-3oc2c1</smiles>

$5 d$<smiles>c1cc2cccc3c4cccc5cccc3c(c1)c-5c4-2</smiles>

6c 
Eswaramoorthy 等 ${ }^{[30]}$ 利用有机硅酸镁薄片作为无机 组分, 嵌入有机发色团四羧基六苯并苯 $7 \mathbf{a}$ 和磺酰罗丹 明 G 7b, 得到一种高量子产率, 合成简易、透明且易于 处理的水凝胶. 随着 $7 \mathbf{b}$ 的加入, 凝胶中 $7 \mathbf{a}$ 的发射强度 降低, 量子寿命缩短, 同时观察到在激发后 $1 \mathrm{~ns}$ 内 $7 \mathbf{b}$ 激 发态数量的急剧增加, 表明存在 $7 \mathbf{a}$ 到 $7 \mathbf{b}$ 的能量转移. 含有 $7 \mathbf{b}(x=0.0065)$ 的凝胶薄膜 $(7 \mathbf{a}$ 苂光 $70 \%$ 猝灭 $)$ 能够 发射高纯度白光, CIE 坐标 $(0.33,0.32)$, 十分接近理想白 光的 $(0.33,0.33)$.<smiles></smiles>

$7 a$

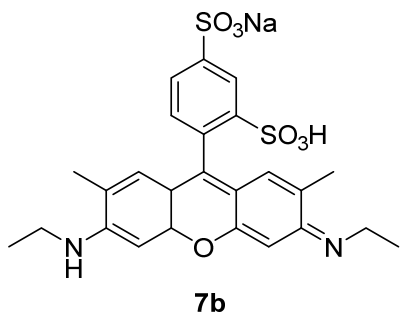

7b
将发色团镶嵌在凝胶体系中有时会造成发色团不 必要的堆积和随溶剂的流失. Thiel 等 ${ }^{[31]}$ 将有机染料以化 学键的形式与无机硅氧化物作用, 并利用甲氧基和三乙 二醇单甲醚基(TGM)修饰得到 $8 \mathbf{a}$ 和 $8 \mathbf{b}$, 能够有效分散 在硅胶中形成有机无机杂化凝胶, 溶剂挥发后得到溶 胶一凝胶玻璃. 喹喔啉衍生物 $8 \mathrm{~b}$ 的凝胶具有等强度的 $550 \mathrm{~nm}$ 的绿光发射峰和 $585 \mathrm{~nm}$ 的黄光发射峰, 在 $\mathbf{8 b}$ 凝 胶中加入蓝色苂光的 $\mathbf{8 a}$, 能够发射亮白色荧光, 但是由 于红色成分的不足, 得到的白光并不纯, CIE 坐标在 $(0.32,0.35)$ 附近.
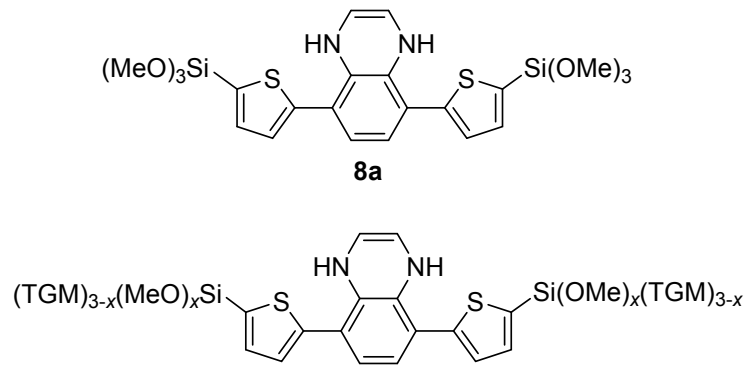

$\mathbf{8 b} x=1,2$

有些凝胶因子, 在溶液态能够形成白光发射, 但是 在凝胶态由于分子结构的限制, 不能发射白光, 如 Das 等 ${ }^{[32]}$ 合成的聚芳醚枝状物 9 在 THF 溶液中具有平衡存 在的酮式和烯醇式两种结构, 在 487 和 $454 \mathrm{~nm}$ 处有两个 发射峰. 随着水的加入, 9 的分子会发生堆积, 限制分子 内化学键的旋转, 增强分子的平面性; 分子内形成的六 元氢键也限制了分子的震动, 减少了非辐射能量损失, 有利于光激发下, 质子从 $\mathrm{OH}$ 转移到亚胺 $\mathrm{N}$ 原子, 提高 光量子产率, 光谱红移, 发射强度增强. 如图 3 所示, 继 续加水至 $20 \% \sim 60 \%$, 介质极性进一步增加, 烯醇式成
为主要构象, 酮式在 $487 \mathrm{~nm}$ 处的发射峰蓝移并逐渐消 失. 唐本忠等 ${ }^{[33]}$ 提出了聚集诱导效应. 对于含水量大于 等于 $50 \%$ 的 9 溶液来讲, 这种广泛聚集可以限制所有的 $\mathrm{C}-\mathrm{C} / \mathrm{N}-\mathrm{N}$ 键旋转或 $\mathrm{C}=\mathrm{N}$ 键异构化, 9 的分子将获得 更平坦的结构，有利于烯醇式分子的平面性和共轭，引 起发射峰 $186 \mathrm{~nm}$ 的斯托克斯位移, 得到 $551 \mathrm{~nm}$ 的最大 发射波长. 继续加水至 $60 \%$ ～99\%, 聚集诱导增强作用 压倒酮醇互变的质子转移作用, $\lambda_{\text {max }}$ 在 $551 \mathrm{~nm}$ 的发射带 强度逐步增加. 在 THF-水的比例从 $100: 0$ 变化为 9 : $1,1: 1$ 和 $1: 99$, 溶液的发光颜色变化为蓝-绿-白-黄. 具有约 $50 \%$ 水的溶液的发光光谱覆盖整个可见光区域 (约 400 700 nm), 实现白光发射. CIE 坐标 $(0.31,0.37)$.

亚苯基-二-1,2-二乙烯基-二- $N$-正辛基吡啶盐(10) 能够在水中能够通过 $\pi-\pi$ 堆积、范德华力和静电作用形 成凝胶, 具有较高的相转变温度、较强的机械强度和较 低的凝胶浓度 ${ }^{[34]}$. 在溶液中, 10 存在着水合作用与自身 $\pi-\pi$ 堆积的一个平衡, 水合时以单体形式存在, 发射天 蓝光, 堆积体发射橙红光. 这种平衡受无机盐和温度的 影响. 无机盐的加入会破坏凝胶因子的水合作用，诱导 堆积体的形成. 1 equiv. $\mathrm{NaBr}$ 加入, 10 单体的吸收峰和 发射峰强度均会降低, 堆积体的吸收峰和发射峰会出 现; 继续加入 $\mathrm{NaBr}$ 到 2 equiv., 单体的吸收峰和发射峰 强度会继续下降, 但是堆积体的光谱不再变化. 温度对 10 堆积的影响表现在升温有利于单体稳定, 降温有利 于堆积体稳定. 加入 1.5 equiv. $\mathrm{NaBr}$ 的 $\mathbf{1 0}$ 溶液从 $65{ }^{\circ} \mathrm{C}$ 降到 $10{ }^{\circ} \mathrm{C}$, 发射颜色发生了从天蓝色到橙红色的变化, 在 $25{ }^{\circ} \mathrm{C}$ 室温下实现白光发射, $\operatorname{CIE}(0.36,0.35)$.

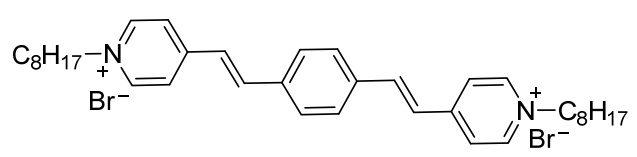

10

\section{3 有机金属化合物作为受体的白光凝胶体系}

金属 Ir 络合物是一种很好的磷光材料，具有很长的 发光寿命和恰好位于可见光区的荧光发射 ${ }^{[35]}$. 可以通 过改变有机芳香配体的结构, 实现对磷光材料发射波 长、发光寿命和量子产率的调控 ${ }^{[36,37]}$.

易涛课题组 ${ }^{[38,39]}$ 以 1,8 -菜二甲酰亚胺衍生物 11a 作 为供体，发橙色光的 Ir 络合物 11b 和 11c 作为受体得到 白光凝胶. 在溶液中, $11 \mathrm{a}$ 和 $11 \mathrm{~b}$ 分子距离较远, $11 \mathrm{~b}$ 的 MLCT 跃迁(有机金属化合物中电子从配体向金属转移 时发生)效率低，能量转移效率只有 $0.5 \% \sim 5.5 \% ; 11 \mathrm{c}$ 波 长合适，但是发光强度低，因此实现白光发射时 $11 \mathrm{~b}$ 或 $11 \mathrm{c}$ 的用量很高. 在凝胶态, 分子距离缩短, 能量转移效 


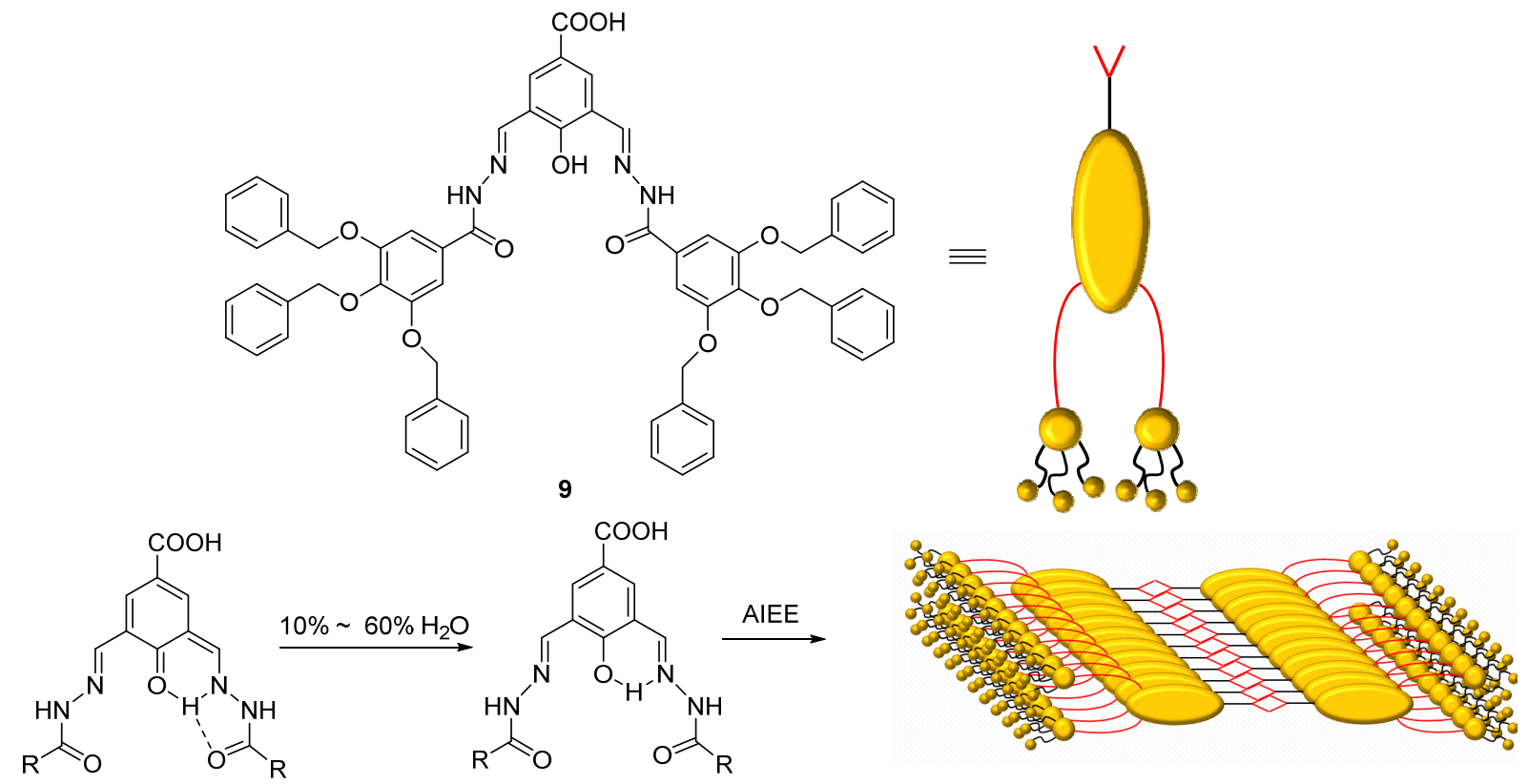

图 3 化合物 9 在 THF-水体系中结构变化示意图

Figure 3 Schematic diagram of structure change of compound 9 in THF- water system

率提高, 得到白光时 $\mathrm{Ir}$ 络合物的用量大大减少, 仅需 $2 \sim 3$ equiv. 的 11b 或 $0.3 \sim 1$ equiv. 的 11c. 11b 的用量为 $2.0 、 2.5 、 3.0$ equiv. 时, 对应的 CIE 坐标为 $(0.25,0.33)$, $(0.30,0.37)$ 和 $(0.31,0.39) ; 11 \mathrm{c}$ 为 0.5 equiv. 时, CIE 坐标是 $(0.33,0.31)$.<smiles></smiles>

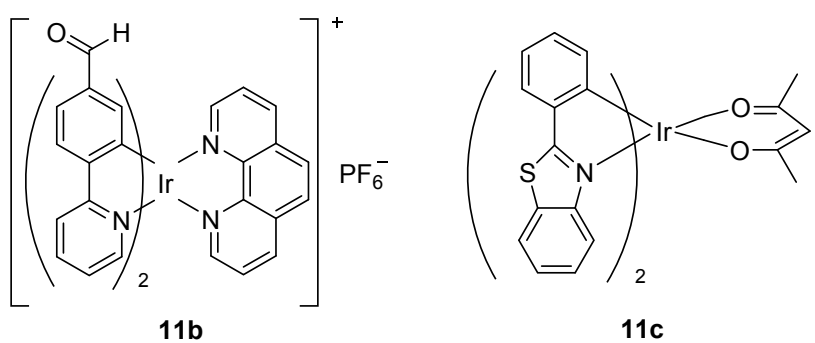

Biradha 等 ${ }^{[00]}$ 用间三吡啶甲氧基苯和 $\mathrm{Cd}(\mathrm{II}), \mathrm{Hg}$ (II) 的氯化物在甲醇一水体系中组装, 得到两种白光有机金 属凝胶, 是一种通过金属离子改变配体光谱, 实现白光 发射的例子. 在 $\mathrm{Cd}$ 凝胶中, $325 \mathrm{~nm}$ 激发下, 最大发射波 长在 $490 \mathrm{~nm}$, 低于配体 12 的 $522 \mathrm{~nm}$ 发射波长, 强度是 12 的 14 倍; $\mathrm{Hg}$ 凝胶的最大发射波长也在 $490 \mathrm{~nm}$, 但强 度较 12 没有较大改变. 两种金属干凝胶的发射波长与 配体 12 相似, 都在 $522 \mathrm{~nm}$ 处, 但更强的 $\pi-\pi$ 堆积导致
发光强度较凝胶态相比大幅度下降. $\mathrm{Cd}$ 凝胶的光量子寿 命为 $3.46 \mathrm{~ns}$, 高于 $\mathrm{Hg}$ 凝胶的 $2.35 \mathrm{~ns}$, 说明 $\mathrm{Cd}$ 凝胶在聚 集态下更坚固，限制分子的旋转和振动，降低了无辐射 弛豫过程, 导致了寿命增加, 苂光增强.<smiles>c1cncc(COc2cc(OCc3cccnc3)cc(OCc3cccnc3)c2)c1</smiles>

\section{4 稀土离子作为受体的白光凝胶体系}

稀土金属发光材料具有强亮度、高量子产率、长激 发态寿命, 以及卓越的光稳定性等优势. 稀土离子作为 受体的白光发射体系, 利用分子的天线作用, 可以有效 放大稀土离子的发光能力; 采用相同的配体进行组装, 较好实现颜色的调控和白光的形成. 将稀土离子置于凝 胶之中既可以固定供受体对的偶极方向，提高能量转移 效率; 又可以有效克服激发态被溶剂间频繁碰撞和振动 耦合产生的非辐射衰减造成的猝灭，有助于白光发 射 ${ }^{[41]}$. 在稀土金属白光凝胶的研究中主要有两种凝胶 形成机制，一种是在凝胶基质中掺杂芳香化合物与稀土 化合物，芳香化合物作为蓝光组分，稀土化合物提供绿 光 $(\mathrm{Tb})$ 和红光 $(\mathrm{Eu})$ 组分; 另一种是缺电子的稀土金属离 子与富电子的有机配体的配位原子作用, 形成有机金属 
配合物, 不仅能够实现白光发射, 还能引入新的非共价 相互作用, 改变凝胶强度.

在凝胶基质中掺杂芳香化合物与稀土化合物的例 子比较少. Zucchi 等 ${ }^{[42]}$ 以硅为凝胶基质, 在其中掺入聚 芴衍生物、 $\mathrm{Tb}^{3+}$ 和 $\mathrm{Eu}^{3+}$ 而获得蓝光、绿光和红光, 具有 非常高的发光量子产率 19\%(蓝), 46\%(绿)和 $21 \%$ (红). 通过三种光的混合, 可以得到白光发射. 在这个体系中, 能量从聚荡衍生物转移到稀土金属, 稀土金属只是作为 发色团, 本身不参与凝胶的形成.

Prasad 等 ${ }^{\left[{ }^{[3]}\right]}$ 以树枝状的多芳基醚 13 为凝胶基质, 实现了由菲、萗、萠供体到针系金属离子受体的能量转 移, 得到了在 $V$ (二甲基亚砜) $: V$ (水) $=1: 9$ 的混合体系 中的白光凝胶. 存在萠、荎、菲的 13 凝胶发蓝光, 稀土 离子加入后, 配体的发射强度降低, 量子寿命缩短, 稀 土离子的发射峰出现, 说明发生了能量转移. 但是这种 转移只发生在凝胶中, 在溶液中不存在, 说明凝胶媒介 能提供一个合适的供受体距离与偶极方向, 对实现供受 体能量转移非常重要. 萗和菲的三线态要高于 $\mathrm{Tb}^{3+}$ 和 $\mathrm{Eu}^{3+}$, 存在芸和菲的三线态到 $\mathrm{Tb}^{3+}$ 和 $\mathrm{Eu}^{3+}$ 的能量转移, 但是萠的三线态低于 $\mathrm{Tb}^{3+}$, 因此只能通过单线态传输, 同时体系中存在着 $\mathrm{Tb}^{3+}$ 到 $\mathrm{Eu}^{3+}$ 的能量转移. 当 $\mathrm{Eu}^{3+}$ 和 $\mathrm{Tb}^{3+}$ 的浓度是 $10^{-4}$ 和 $10^{-2} \mathrm{~mol} / \mathrm{L}$, 菲、萗、芘的浓度为 $10^{-7} 、 10^{-5} 、 10^{-8} \mathrm{~mol} / \mathrm{L}$ 时, 获得的白光最理想, $\mathrm{CIE}$ 坐 标对应 $(0.33,0.32) 、(0.35,0.37) 、(0.35,0.33)$.

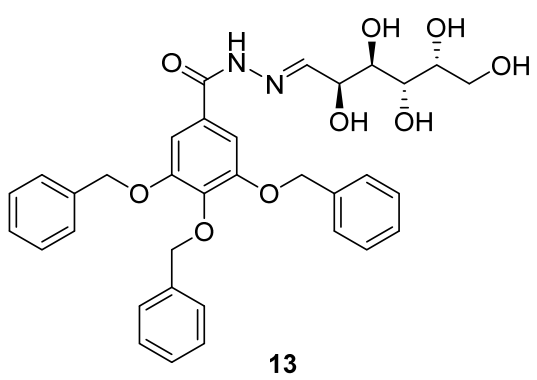

Maitra 等 ${ }^{[44]}$ 报道了以胆酸钠 14 为凝胶因子, 掺杂 2,3-二差基萗、 $\mathrm{Tb}^{3+}$ 得到的绿色凝胶和掺杂萠、 $\mathrm{Eu}^{3+}$ 得 到的洋红色凝胶. 在洋红色凝胶中加入 2,3-二羟基芸和 $\mathrm{Tb}^{3+}$, 会发生 $\mathrm{Tb}^{3+}$ 到 $\mathrm{Eu}^{3+}$ 的能量转移, 调控光的颜色从 绿色到黄色, 到粉色, 再到红色. 通过减少 $\mathrm{Eu}^{3+}$ 的量, 减少红光组分; 增加 2,3-二羟基䒺的量, 平衡 $\mathrm{Tb}^{3+}$ 的绿 光, 有利于发射光向白光接近. 当 $\mathrm{Tb}^{3+}$ 为 $4.55 \mathrm{mmol} / \mathrm{L}$, $\mathrm{Eu}^{3+}$ 为 $28 \mu \mathrm{mol} / \mathrm{L}, 2,3$-二羟基萗为 $400 \mu \mathrm{mol} / \mathrm{L}$, 萠为 $0.18 \mu \mathrm{mol} / \mathrm{L}, 14$ 为 $15.4 \mathrm{mmol} / \mathrm{L}$ 时, 如愿得到白光凝胶, 光量子产率 $6 \%, \mathrm{CIE}$ 坐标 $(0.33,0.37)$. 在绿色凝胶中, 加入 $\mathrm{Eu}^{3+}$, 可以产生黄光发射. 由于 2,3-二羟基萗到 $\mathrm{Tb}^{3+}$ 的能量转移效率太高, 造成蓝光成分的不足, 无法 得到白光. 通过在体系中引入无苂光的金属 $\mathrm{Zn}$, 占据
2,3-二羟基萗的络合位点, 阻止其向 $\mathrm{Tb}^{3+}$ 的能量转移, 在 $\mathrm{Tb}^{3+} 4.55 \mathrm{mmol} / \mathrm{L}, \mathrm{Eu}^{3+} 110 \mu \mathrm{mol} / \mathrm{L}, \mathrm{Zn}^{2+} 2.84$ $\mathrm{mmol} / \mathrm{L}, 2,3$-二羟基萗 $200 \mu \mathrm{mol} / \mathrm{L}, 1415.4 \mathrm{mmol} / \mathrm{L}$ 时获 得白光发射, 光量子产率 $7 \%$, CIE 坐标 $(0.33,0.34)$.<smiles>CC(CCC(=O)O[Na])[C@H]1CC[C@H]2[C@H]3[C@H](C[C@H](O)[C@]21C)[C@@]1(C)CC[C@H](O)C[C@@H]1C[C@H]3O</smiles>

对氯苯酚 15a 分子堆叠成 “链”, 利用二(2-乙基己 基)磺基琥珀酸 $15 \mathrm{~b}$ 的氢键吸附在链的外部, 链聚集产 生纤维束, 可以形成凝胶 ${ }^{[45]}$. 在凝胶基质中引入六氟乙 酰丙酮 $15 \mathrm{c}$ 和邻菲罗啉 $15 \mathrm{~d}$ 为配体, $\mathrm{Eu}^{3+}$ 和 $\mathrm{Tb}^{3+}$ 为核的 配位化合物, 可以发射橙色光和绿色光, 混合得到黄色 光. 将不具备苂光性能的苯酚换成 2-荎酚 $15 \mathrm{e}$, 制备 $15 \mathrm{e}$ 和 $15 \mathrm{~b}$ 的凝胶, 具备蓝色发光能力 ${ }^{[46]} . \mathrm{Eu}^{3+}$ 络合物加入 后，在苂光光谱上能够明显看见 $\mathrm{Eu}^{3+}$ 离子的发射峰的 出现, 发生了 $15 \mathrm{e}$ 到 $\mathrm{Eu}^{3+}$ 络合物的能量转移. 最终在 $15 \mathrm{e}$ 和 $\mathrm{Eu}^{3+}$ 络合物的共同作用下, 得到略带粉红色的白 光凝胶.

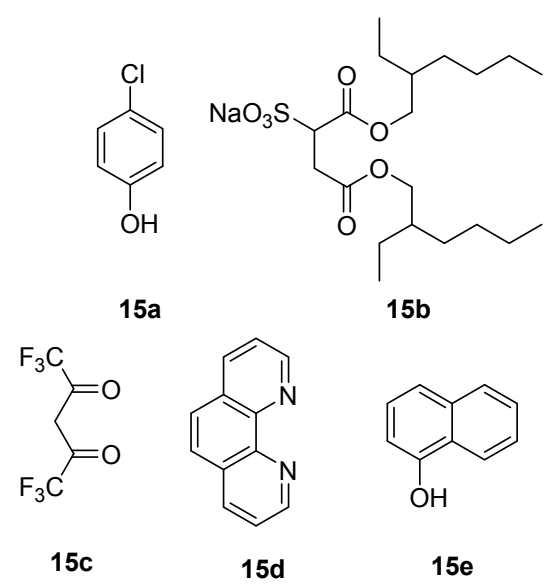

第二种机制形成的白光凝胶中有机配体主要为含 氮杂环化合物. Chang 等 ${ }^{[47]}$ 制备的凝胶因子 $16 \mathbf{a} 、 16 \mathrm{~b}$, 在 癸烷中能够形成金属凝胶. 在凝胶中, 邻二氮杂菲配体 吸收能量, 跃迁到激发态, 然后将激发态的能量转移给 稀土离子, 激发稀土离子发光. 以 $\mathrm{Eu}^{3+}$ 为金属中心的凝 胶发红色光, 以 $\mathrm{Tb}^{3+}$ 为金属中心的凝胶发绿色光, 将 $\mathrm{Eu}^{3+}$ 和 $\mathrm{Tb}^{3+}$ 按照质量比 $1: 19$ 可以得到具有白光发射的 超分子凝胶, CIE 坐标 $(0.36,0.30)$. 该白光发射混合凝胶 的最低成胶浓度是 $w=0.013$, 介于 $\mathrm{Eu}^{3+}$ 凝胶的 $w=$ 0.007 和 $\mathrm{Tb}^{3+}$ 凝胶的 $w=0.019$ 之间. 这种邻二氮杂菲配 位的凝胶因子能够和两分子 1,3-二酮基团配位形成更大 的超分子结构 16c 和 16d. 将两种大聚合物按照 $3: 1$ 的 质量比例混合在癸烷中能够形成均相的混合凝胶，具备 
白光发射性能.

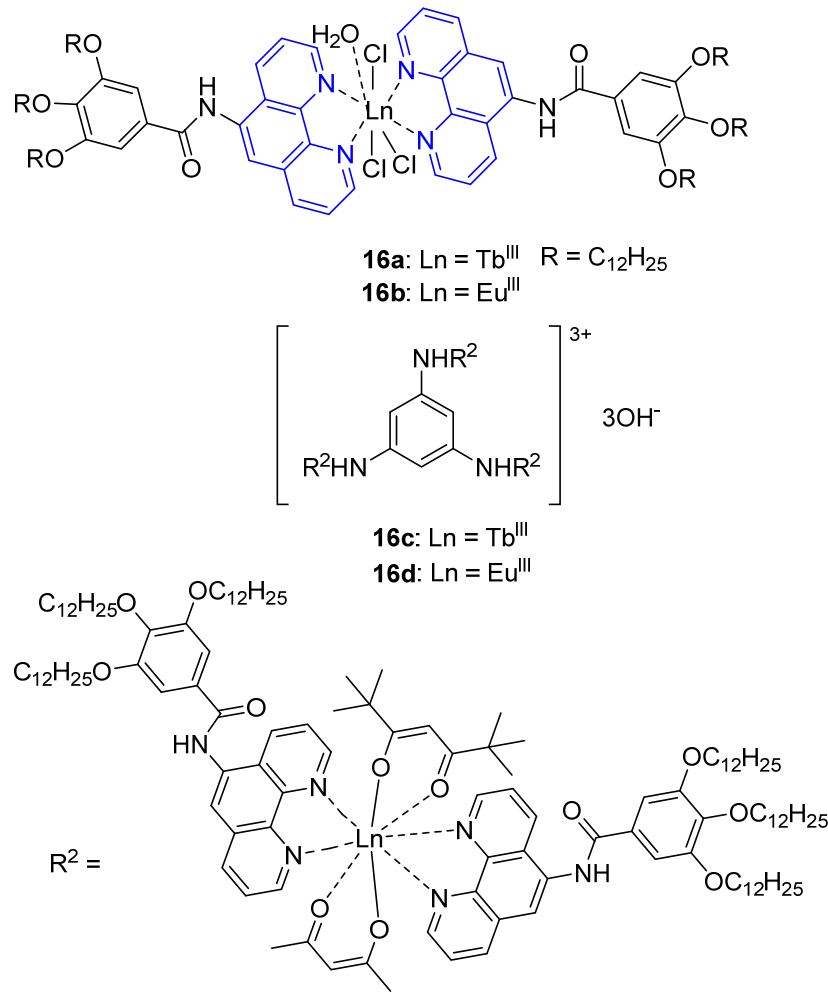

三联吡啶的三个吡啶环形成一个大的共轭体系, 具 有很强的 $\sigma$ 给电子能力, 配合物中存在金属到配体的 $\mathrm{d}-\pi^{*}$ 反馈成键作用, 因而能与大多数金属离子形成稳定 结构的配合物. 其三个吡啶基上的孤对电子具有非常好 的配位能力, 和稀土金属络合后能够发生有效的能量转
移，并发射不同颜色的光 ${ }^{[2,48]}$. 三联吡啶的衍生物又是 一种非常好的凝胶因子，具有特定结构的三联吡啶衍生 物能够在氢离子或者金属离子存在下形成凝胶 ${ }^{[49,50]}$.

Holten-Andersen 等 ${ }^{[51]}$ 将三联吡啶衍生物 17 (未配位, 蓝色)、17a(红色)、17b(绿色)按照一定比例复配，获得 的白光聚合物凝胶对超声具有响应性能. 在 $25{ }^{\circ} \mathrm{C}$ 超声 $5 \mathrm{~min}$, 白光凝胶会变成蓝光溶胶, $\mathrm{Eu}^{3+}$ 的红色成分减少. 利用气相沉积法可以得到高强度的白光固体薄膜. 该薄 膜对温度、 $\mathrm{pH}$ 等刺激具有响应性能. 温度从 $-196{ }^{\circ} \mathrm{C}$ 到 $60{ }^{\circ} \mathrm{C}$ 变化, 白光薄膜经历一次从绿色到红色的转变, 说明随着温度升高, 内部能量从 $\mathrm{Tb}^{3+}$ 到 $\mathrm{Eu}^{3+}$ 的一个转 变; 薄膜暴露在酸性或碱性蒸汽中, 由于稀土离子和三 联吡啶间的作用被破坏，白光会向蓝光变化. 这种端位 引入稀土离子作为发色团的高分子发光凝胶避免了通 过主链共轭聚合形成较大的共轭面积, 较好的保持了溶 解性、熔融性及加工性能. 但发色团在聚合物的末端, 会导致主体部分分子量过大，发光基团含量低，苂光减 弱.

Maji 等 ${ }^{[52]}$ 以 9.10-二苯基葱为核连接三联吡啶得到 一种低分子量凝胶因子 18, 可在 $\mathrm{CHCl}_{3}: \mathrm{THF}=2: 1$ 的 混合溶剂中形成凝胶. $\mathrm{Tb}^{3+}$ 和 $\mathrm{Eu}^{3+}$ 掺入后, 凝胶保留着 18 的组装结构，同时产生了金属有机的配位协同作用， 形成更高度有序的金属有机聚合物. 改变两种稀土金属 的比例, 在 $\mathrm{Tb}^{3+}: \mathrm{Eu}^{3+}=1: 2$ 时, 获得白光凝胶, $\mathrm{CIE}$ 坐标 $(0.28,0.34)$, 量子产率 $5 \%$.

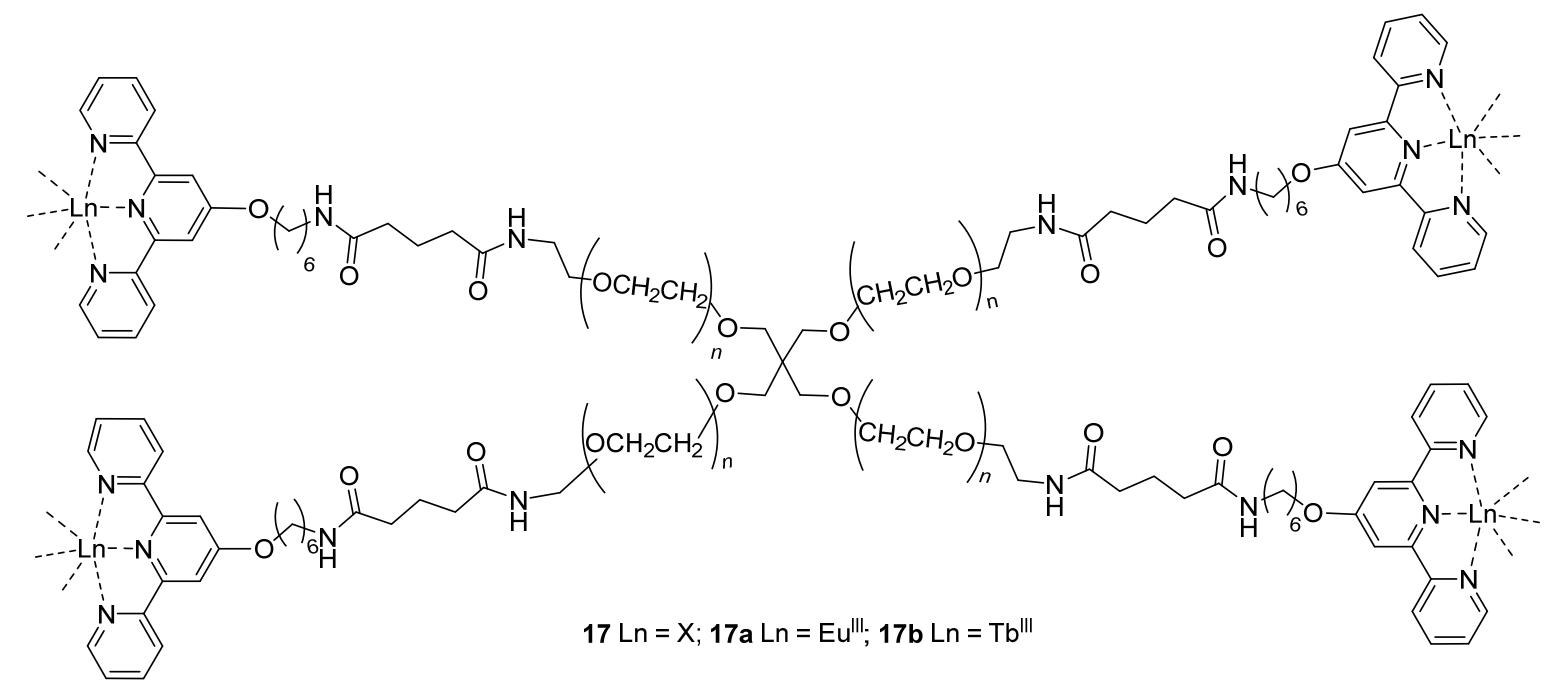<smiles>O=C(NCCCNc1cc(-c2ccccn2)nc(-c2ccccn2)c1)c1ccc(-c2c3ccccc3c(-c3ccc(C(=O)NCCCNc4cc(-c5ccccn5)nc(-c5ccccn5)c4)cc3)c3ccccc23)cc1</smiles> 


\section{5 应用前景}

白光凝胶相较于其他白光材料, 具有以下的优点: (1)克服了液体的无定型性, 带来了封装上的便利, 能够 有效避免泄露带来的污染; (2)降低了纯固体的刚性与硬 度, 提升了自身的柔性与灵活性, 易于塑形与切割, 形 变与恢复; (3)发光组分的实际浓度很低, 有效降低材料 成本; (4)灵活的相转变过程与敏感的物理响应性; (5)较 高的稳定性与较长的使用寿命; (6)由干凝胶所制备的白 光薄膜制作工艺简单, 尺度易于控制, 发光效果良好, 是性能优异的纳米材料. 同时, 白光凝胶也存在以下的 一些不足: (1)对化学刺激的响应时间长于白光溶液; (2) 机械强度不如白光固体; (3)组成凝胶的非共价相互作用 在强刺激(强机械力, 高温等)下会被破坏; (4)白光薄膜 制备中需要溶剂蒸发, 周期较长.

目前, 白光凝胶的研究还处在起步阶段, 实际应用 还胗胗无几, 但其独特的性质决定其在未来潜在的价 值.

在显示材料领域，白光凝胶制成的发光薄膜，具有 非常薄的薄膜厚度和非常好的光学表达, 可以有效减少 凝胶因子的使用量, 降低材料成本; 具备损坏后自我修 复性能(基于非共价力的破坏与形成)的白光凝胶制成的 显示器件, 拥有更长久的使用寿命和自我修复的能力. 如图 4 所示, 涂抹 7a、7b 白光凝胶的紫外灯, 在断开电 源时与普通紫外灯无明显不同, 接通电源后, 有凝胶涂 层的灯发明亮的纯白光, 而没有涂层的灯发昏暗的蓝 光 ${ }^{[30]}$. 用凝胶在紫外灯上写字, 断开电源时, 字体透明
不可见; 接通电源后, 文字能够清晰地发射白光, 清晰 可读, 实现信息传达. 把凝胶涂布在透明的柔性塑料薄 板上可以得到白光发射薄板, 发光性能不受薄板折曲和 卷曲的影响, 可以实现柔性白光照明. 将 8 系列不同组 分, 不同粘度的凝胶旋涂在各种基底上可以形成多微孔 的薄片，适合设计低成本的玻璃分散液晶 (GDLC $)^{[31]}$. 如图 5 所示, 18 系列的白光凝胶可以旋涂在各种基底上, 获得强烈的绿、红、黄和白光. 将这种凝胶涂在蓝色的 发光二极管 (LED) 上，可以构建白光发射二极管 (WLED), 实现明亮的白光发射 ${ }^{[52]}$.

在智能材料领域, 由于白光复杂的组成, 具有对外 界刺激更多样的表达. 探针检测方面, 11 系列是优异的 半胱氨酸检测探针, 在混合凝胶中加入 40 equiv. 半胱氨 酸, $11 \mathrm{~b}$ 上的醛基和半胱氨酸反应生成了四氢噻唑衍生 物. 凝胶会由黄色变为白色, 发射光会从白色变为蓝色, 上清液会由浅黄色变为无色，如图 6 所示. 这种凝胶很 容易做成薄膜, 可以用于裸眼就能看到的半胱氨酸检测 探针 ${ }^{[38]} .12$ 系列的白光凝胶对硝基芳香化合物有很好的 响应 ${ }^{[40]} . \mathrm{Cd}$ 凝胶旋涂的薄片暴漏在硝基苯饱和蒸汽中 5 $\min$, 由于缺电子的芳香苯与 $\mathrm{Cd}$ 凝胶的富电子芳香环表 面发生了电子转移，造成 $90 \%$ 的荧光猝灭. 这种薄膜对 于硝基芳烃的检测灵敏度高、选择性高、环保、可多次 使用. 基于白光凝胶对于刺激的响应性能，未来，对于 温度和 $\mathrm{pH}$ 有灵敏响应的白光凝胶可以应用于环境监测; 对于水蒸气、二氧化碳等常见气体具有响应的白光凝胶 更是有望在食品安全检测、钻井开采等领域实现应用.

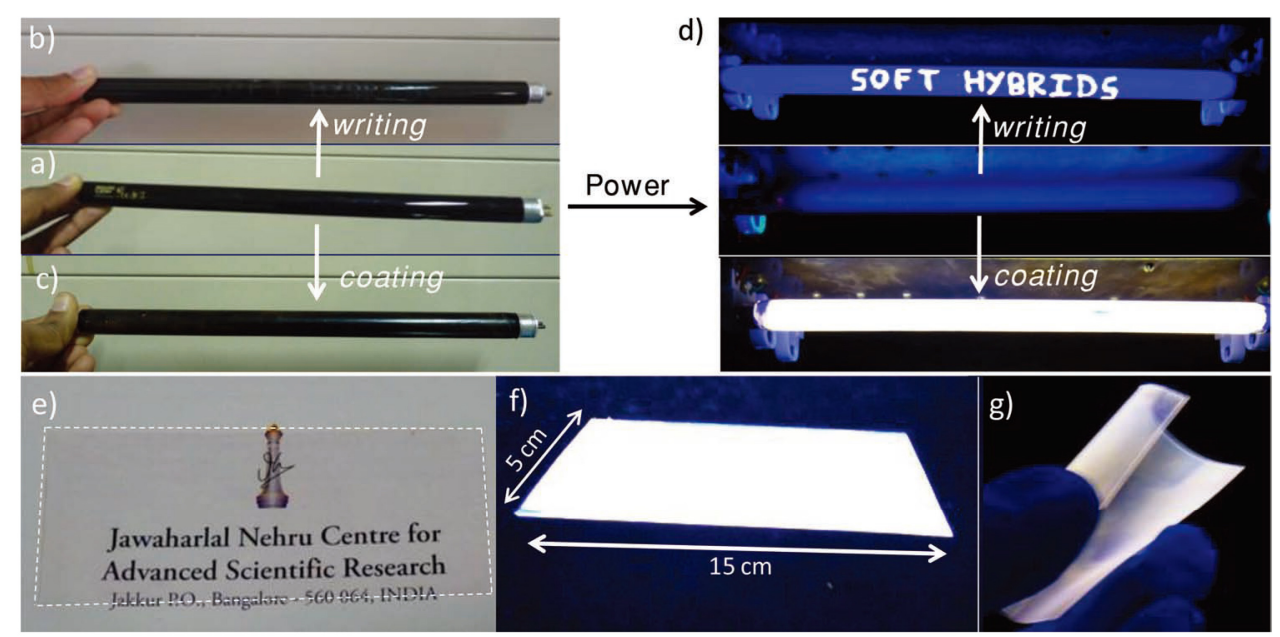

图 4 包含 $0.65 \mathrm{~mol} \% 7 \mathbf{b}$ 受体的 $7 \mathbf{a}$ 凝胶成型过程的证明

Figure 4 Demonstrations of the solution processability of $7 \mathbf{a}$ containing $0.65 \mathrm{~mol} \%$ of $7 \mathbf{b}$

The soft-hybrid hydrogels were used to paint or write various substrates: a $\sim$ ) hybrids were used to paint and write on commercial UV-lamps $(365 \mathrm{~nm}$, surface area = $125 \mathrm{~cm} \mathrm{2);} \mathrm{a)} \mathrm{uncoated} \mathrm{lamp,} \mathrm{b)} \mathrm{written} \mathrm{as} \mathrm{'SOFT} \mathrm{HYBRIDS'} \mathrm{on} \mathrm{the} \mathrm{surface} \mathrm{of} \mathrm{the} \mathrm{lamp} \mathrm{and} \mathrm{c)} \mathrm{lamp} \mathrm{fully} \mathrm{coated} \mathrm{with} \mathrm{the} \mathrm{soft-hybrids.} \mathrm{The}$ hybrid coating is diffi cult to visualize under the normal light (4b, c), as they are transparent. d) Hybrid-coated lamps are exposed to the UV irradiation by glowing the lamps, which showed bright white light for both written letters and the fully-coated lamp. e) A flexible transparent sheet $(5 \mathrm{~cm} \times 15 \mathrm{~cm})$ after painting with the hybrids, which retains its transparency even after coating (the dotted line indicates the boundary of the sheet). f), g) The hybrid coated transparent sheet shows white-light emission when exposed to the UV-light. All the images were taken after drying the coated substrates in air for $6 \mathrm{~h}$ 

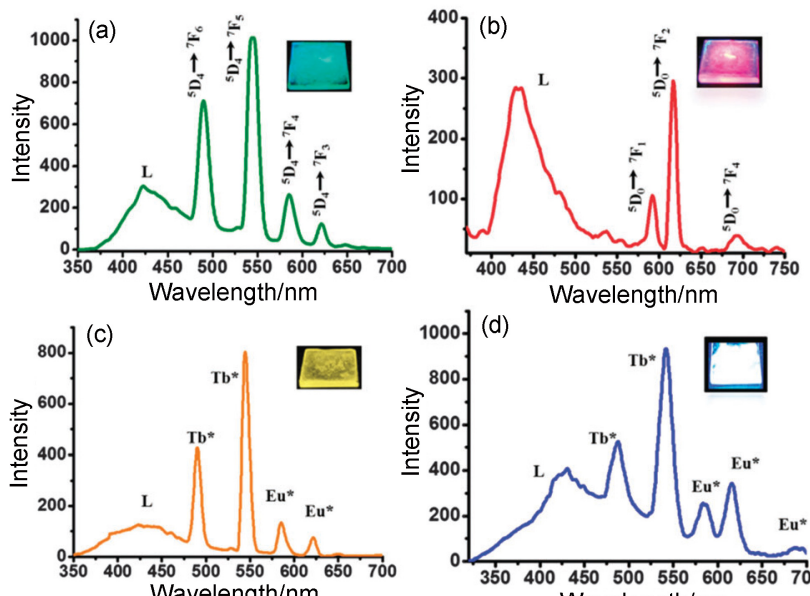

(e)
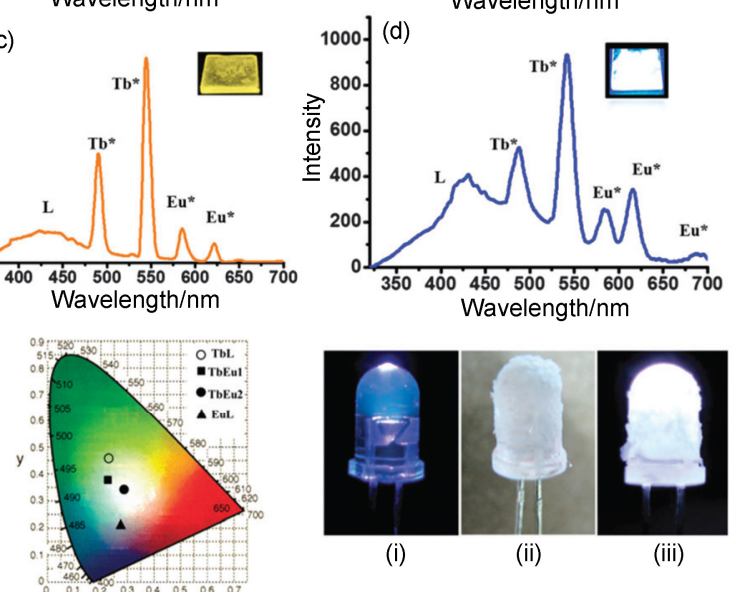

(i)

(ii)

(iii)

图 5 (a) TbL, (b) EuL, (c) TbEu1, (d) TbEu2 的发射光谱 $\left(\lambda_{\mathrm{ex}}=\right.$ $280 \mathrm{~nm}$ ); (e) TbL(空心圆)、EuL(三角形)、TbEu1(方形)与 TbEu2 (实心圆)的 CIE 坐标; (f)(i)LED 在紫外灯下的照片; (ii)涂覆 $\mathrm{TbEu} 2$ 凝胶的 LED 在日光灯下的照片; (iii)涂覆 TbEu2 凝胶的 LED 在紫外灯下的照片

Figure 5 Emission spectra of (a) TbL, (b) EuL, (c) TbEu1 and (d) $\mathrm{TbEu} 2\left(\lambda_{\mathrm{ex}}=280 \mathrm{~nm}\right)$. (e) CIE chromatography of TbL (circle), EuL (triangle), TbEu1 (square) and TbEu2 (solid circle). (f) Photograph of an illuminating ultraviolet LED (i), same LED coated with TbEu2 gel under day light (ii) and LED showing bright white light after switching on the LED (iii)
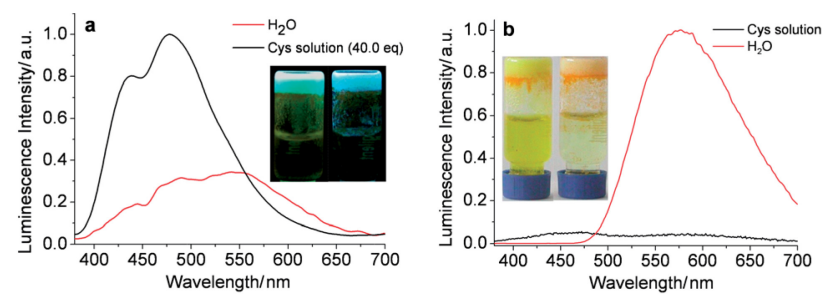

图 6 分别加入半胱氨酸与水 $24 \mathrm{~h}$ 后的凝胶(a)与上清液(b)的 发射光谱 $\left(c_{1 \mathrm{~b}}=25 \mathrm{mg} \mathrm{mL}^{-1}, \lambda_{\mathrm{ex}}=356 \mathrm{~nm}\right)$

Figure 6 Luminescence spectra of (a) the gel part and (b) the upper solution after addition of Cys solution and water, respectively for $24 \mathrm{~h}\left(c_{\mathrm{lb}}=25 \mathrm{mg} \mathrm{mL}^{-1}, \lambda_{\mathrm{ex}}=356 \mathrm{~nm}\right)$

The insets of $\mathrm{a}$ and $\mathrm{b}$ are the emission image and bright image of the samples with water (left) and Cys solution (right), respectively

\section{6 小结}

综上可见，白光凝胶体系具有以下特点：(1)白光凝 胶由多种作用力组成, 对外界的物理化学刺激具有在光 谱颜色, 聚集状态等方面的多个响应位点; (2)凝胶实现 的组装改变分子的距离和偶极方向, 调控光谱结构, 使
供受体间能级更加匹配，提高能量转移效率，实现白光 发射; (3)凝胶可以有效减少溶剂分子间碰撞造成的能量 衰减, 提高发光效率; (4)通过改变凝胶因子和溶剂的比 例, 可以实现白光凝胶到白光液体和白光固体的转变.

但是关于白光凝胶的研究总体较少, 很多机理性的 研究还不到位; 组分间的能量转移停留在经验阶段, 还 无法做到用理论预测现象; 已经得到的白光发射凝胶体 系存在着发光效率低，耐久度差，凝胶强度低的弊端； 工业化还很遥远. 然而一旦解决上述问题，白光凝胶将 以其低廉的合成成本，简易的加工条件，灵活的分子组 装, 实现在光学器件、照明设备、光学传感、显示材料、 环境监测、纳米发光材料、太阳能转化、生物成像等领 域大的突破.

\section{Referenes}

[1] Kamtekar, K. T.; Monkman, A. P; Bryce, M. R. Adv. Mater. 2010 22, 572 .

[2] Chen, Z. L.; Li, H. L.; Wei, J.; Xiao, Y.; Yu, H. B. Chin. J. Org. Chem. 2015, 35, 789 (in Chinese). (陈忠林，李红玲，韦驾，肖义，于海波，有机化学，2015，35, 789.)

[3] Willis-Fox, N.; Kraft, M.; Arlt, J.; Scherf, U.; Evans, R. C. $A d v$. Funct. Mater. 2016, 26, 532.

[4] Chen, P.; Holten-Andersen, N. Adv. Opt. Mater. 2015, 3, 1041.

[5] Maiti, D. K.; Banerjee, A. Chem. Commun. 2013, 49, 6909.

[6] Melucci, M.; Zambianchi, M.; Barbarella, G.; Manet, I.; Montalti, M. J. Mater. Chem. 2010, 20, 9903.

[7] Balan, B.; Vijayakumar, C.; Ogi, S.; Takeuchi, M. J. Mater. Chem. 2012, 22, 11224.

[8] Gai, F.Y.; Zhou, T. L.; Zhang, L. G.; Li, X.; Hou, W. J.; Yang, X. C.; Li, Y. T.; Zhao, X. G.; Xu, D.; Liu, Y. L.; Huo, Q. S. Nanoscale 2012, 4, 6041

[9] Zhang, X.; Rehm, S.; Safontsempere, M. M.; Würthner, F. Nat Chem. 2009, 1, 623 .

[10] Babu, S. S.; Aimi, J.; Ozawa, H.; Shirahata, N.; Saeki, A.; Seki, S.; Ajayaghosh, A.; Möhwald, H.; Nakanishi, T. Angew. Chem., Int. Edit. 2012, 124, 3447.

[11] Praveen, V.K.; Ranjith, C.; Armaroli, N. Angew. Chem. Int. Edit. 2014, 53, 365.

[12] Sun, H. B.; Liu, S. J.; Zhao, Q.; Huang, W. Chin. J. Chem. 2015, 33,1140 .

[13] Wang, T.; Wang, Z.Y.; Xie, D.Y.; Wang, C.; Zhen, X. L.; Li, Y. J.; Yu, X. D. RSC Adv. 2015, 5, 107694

[14] Raymo, F. M.; Tomasulo, M. Chem. Soc. Rev. 2005, 34, 327.

[15] Hissler, M.; Harriman, A.; Khatyr, A.; Ziessel, R. Chem. Eur. J. 1999, $5,3366$.

[16] Verhoeven, J. W. J. Photochem. Photobiol. C 2006, 7, 40.

[17] Zhang, C.; Zhao, Y. A.; Yao, J. N. New J. Chem. 2011, 35, 973.

[18] Ajayaghosh, A.; Praveen, V. K.; Vijayakumar, C. Chem. Soc. Rev. 2008, 37, 109.

[19] Farinola, G. M.; Ragni, R. Chem. Soc. Rev. 2011, 40, 3467.

[20] Babu, S. S.; Kartha, K. K.; Ajayaghosh, A. J. Phys. Chem. Lett. 2010, 1,3413

[21] Ajayaghosh, A.; Praveen, V. K.; Vijayakumar, C.; George, S. J. Angew. Chem., Int. Edit. 2007, 119, 6376.

[22] Vijayakumar, C.; Praveen, V. K.; Ajayaghosh, A. Adv. Mater. 2009 $21,2059$.

[23] Giansante, C.; Raffy, G.; Fer, C. S.; Rahma ,H.; Kao, M. T. J. Am Chem. Soc. 2011, 133, 316.

[24] Abbel, R.; Grenier, C.; Pouderoijen, M. J.; Stouwdam, J. W.; Leclère, P. E. L. G.; Sijbesma, R. P.; Meijer, E. W.; Schenning, A. P. 
H. J. J. Am. Chem. Soc. 2009, 131, 833.

[25] Giansante, C.; Schäfer, C.; Raffy, G.; Guerzo, A. D. J. Phys. Chem. C 2012, 116, 21706

[26] Abbel, R.; Weegen, R. V. D.; Pisula, W.; Surin, M.; Leclère, P.; Lazzaroni, R.; Meijer, E. W.; Schenning, A. P. H. J. Chem. Eur. J. 2009, 15, 9737.

[27] Bairi, P.; Roy, B.; Nandi, A. K. Chem. Commun. 2012, 48, 10850.

[28] Bairi, P.; Roy, B.; Chakraborty, P.; Nandi, A. K. ACS Appl. Mater. Inter. 2013, 5, 5478 .

[29] Pallavi, P.; Bandyopadhyay, S.; Louis, J.; Deshmukh, A.; Patra, A. Chem. Commun. 2017, 53, 1257 .

[30] Rao, K. V.; Datta, K. K. R.; Eswaramoorthy, M.; George, S. J. $A d v$. Mater. 2013, 25, 1713.

[31] Hemgesberg, M.; Bay, S.; Schütz, S.; Dörr, G.; Ernst, S.; Kowalsky, W.; Müller, T. J. J.; Wagenblast, G.; Thiel, W. R. Microporous Mesoporous Mater. 2013, 174, 1.

[32] Maity, A.; Ali, F.; Agarwalla, H.; Anothumakkoolb, B.; Das, A. Chem. Commun. 2015, 51, 2130

[33] Mei, J.; Leung, N. L. C.; Kwok, R. T. K.; Lam, J. W. Y.; Tang, B. Z. Chem. Rev. 2015, 115, 11718 .

[34] Bhattacharya, S.; Samanta, S. K. Chem.-Eur. J. 2012, 18, 16632.

[35] Yadav, Y. J.; Heinrich, B.; Luca, G. D.; Talarico, A. M.; Mastropietro, T. F.; Ghedini, M.; Donnio, B.; Szerb, E. I. Adv. Opt. Mater. 2013, 1, 844.

[36] Kishimura, A.; Yamashita, T.; Aida, T. J. Am. Chem. Soc. 2005, 127, 179.

[37] Wang, F. F.; Tao, Y. T.; Huang, W. Acta Chim. Sinica 2015, 73, 9 (in Chinese).

(王芳芳, 陶友田, 黄维, 化学学报, 2015, 73, 9.)

[38] Cao, X.; Wu, Y.; Liu, K.; Yu, X.; Wu, B. J. Mater. Chem. 2012, 22,
2650.

[39] Cao, X. H.; Lan, H. C.; Li, Z. H.; Mao, Y. Y.; Chen, L. M.; Wu, Y. Q.; Yi, T. Phys. Chem. Chem. Phys. 2015, 17, 32297.

[40] Roy, S.; Katiyar, A. K.; Mondal, S. P.; Ray, S. K.; Biradha, K. ACS Appl. Mater. Inter. 2014, 6, 11493

[41] Paoli, G. D.; Olic, Z .D.; Rizzo, F.; Cola, L. D.; Gtle, F. V. $A d v$. Funct. Mater. 2007, 17, 821 .

[42] Huang, X.; Zucchi, G. L.; Tran, J.; Pansu, R. B.; Brosseau, A.; Geffroy, B.; Nief, F. O. New J. Chem. 2014, 38, 5793.

[43] Kumar, P.; Soumya, S.; Prasad, E. ACS Appl. Mater. Inter. 2016, 8, 8068.

[44] Laishram, R.; Bhowmik, S.; Maitra, U. J. Mater. Chem. C 2015, 3 , 5885 .

[45] Simmons, B. A.; Taylor, C. E.; Landis, F. A.; John, V. T.; McPherson, G. L.; Schwartz, D. K.; Moore, R. J. Am. Chem. Soc. 2001, 123, 2414.

[46] Katsube, S.; Harada, T.; Umecky, T.; Takamuku, T.; Kaji, T.; Hiramoto, M.; Katsumoto, Y.; Nishiyama, K. Chem. Lett. 2014, 43, 1861.

[47] Kim, H.; Chang, J. Y. RSC Adv. 2013, 3, 1774.

[48] Ghosh, K.; Balog, E. R. M.; Kahn, J. L.; Shepherd, D. P.; Martinez, J. S.; Rocha, R. C. Macromol. Chem. Phys. 2015, 216, 1856.

[49] Oxana, K.; Ronan, D.; Santos, C. D.; Markus, B.; Kruger, P. E. Angew. Chem., Int. Edit. 2012, 51, 7208 .

[50] Sambri, L.; Cucinotta, F.; Paoli, G. D.; Stagnic, S.; Colab, L. D. New J. Chem. 2010, 34, 2093.

[51] Chen, P.; Li, Q.; Grindy, S.; Holten-Andersen, N. J. Am. Chem. Soc. 2015, 137, 11590

[52] Sutar, P.; Suresh, V. M.; Maji, T. K. Chem. Commun. 2015, 51, 9876.

(Li, L.) 